\title{
OCORRÊNCIA DE Austrodiplostomum spp. (PLATYHELMINTHES: DIGENEA) EM OLHO DE PEIXES COLETADOS NA REPRESA DE BARIRI NO ESTADO DE SÃO PAULO
}

\author{
OCCURRENCE OF Austrodiplostomum spp. (PLATYHELMINTHES: \\ DIGENEA)COLLECTED IN FISH EYE ON BARIRI RESERVOIR \\ IN SÃO PAULO STATE
}

\author{
T. ROSENDO ${ }^{1}$; L. A. PIRES ${ }^{1}$; T. M. LIMA ${ }^{1}$;Y. G. MARANGONI ${ }^{1}$; F. Z. ARAUJO ${ }^{1}$; R. CANAL ${ }^{1}$; \\ M. F. ÁRABE FILHO; A. M. ANTONUCCI ${ }^{2 *}$
}

\begin{abstract}
RESUMO:
Metacercarias do gênero Austrodiplostomum (Platyhelminthes: Digenea) são frequentemente encontradas parasitando olhos de peixes de água doce devido a sua ampla distribuição geográfica e baixa especificidade. No entanto, a simples identificação morfológica de espécie não é aconselhável devido à alta similaridade interespecífica. Sabidamente os digenéticos utilizam-se dos peixes como hospedeiros intermediários, concluindo seu ciclo de vida geralmente em aves piscívoras. A parasitose ocular provoca alterações patológicas que afetam a visão do peixe, fazendo com que este fique mais tempo na superfície da coluna de água, facilitando, assim, sua predação. Objetivou-se com este trabalho relatar a ocorrência de metacercárias de Austrodiplostomum sp. em $80 \%$ dos 10 espécimes de Plagioscion squamosissimus (Heckel, 1840) coletados no reservatório de Bariri localizado no rio Tietê no Estado de São Paulo em Setembro de 2014 e identificados no Laboratório de Parasitologia Veterinária da FAEF em Garça. Os índices parasitários encontrados para estes peixes coletados foram: intensidade média, 15,25; abundância média 12,2 e amplitude 4-21. Na região de coleta foram encontrados muitos animais piscívoros que podem se alimentar de P. squamosissimus, mesmo esta espécie sendo exótica neste ambiente. Este registro parasitológico aumenta a distribuição geográfica do parasito, contudo, estudos epidemiológicos e morfológicos utilizando métodos de biologia molecular devem ser realizados para a compreensão da distribuição e biologia da espécie de Austrodiplostomum sp. que ocorre na região.
\end{abstract}

PALAVRAS-CHAVE: SANIDADE. PLAGIOSIUM SQUAMOSISSIMUS. PESCA. DIGENÉTICOS.

AGRADECIMENTOS: FAEF

ÁREA TEMÁTICA: Doenças Parasitárias 